\title{
An overview of the Japanese quotative itta and itte ita
}

\author{
Hironori Nishi \\ University of Memphis
}

\begin{abstract}
The present study provides an overview of the quotative utterances made with itta (past form of iu 'to say') and itte ita (the combination of $i u$ and the past form of the -te iru construction) in naturally occurring conversations in Japanese. The examination of approximately 13 hours of conversations shows that itta is used in $91.1 \%$ of first-person quotations ('I said that...'). In second-person ('you said that...') and third-person ('he/she said that...') quotations, itte ita is used in $90.0 \%$, and $77.3 \%$ of the cases, respectively. The present study argues that the high percentage of itte ita for second- and third-person quotative utterances is due to the fact that the -te iru construction, which is included in itte ita, is used as an evidential marker. The present study also analyzes the deviant cases from the dominant pattern (i.e. using itta for third-person utterances), and demonstrates how -te iru's evidential function is utilized manipulatively in conversation.
\end{abstract}

Keywords: Japanese, pragmatics, subjectivity, evidential marker, psychological impact, itta, itte ita, -te iru

\section{Introduction}

It has been recognized that the Japanese verb iu 'to say' is one of the most frequently used expressions used in quotative utterances in Japanese. In order to provide an overview of quotative utterances made with $i u$ in Japanese, this paper will examine a corpus of naturally occurring conversations between native speakers of Japanese, and discuss the usages of the verb along with the conversational contexts in which it is used. 


\section{1 itta and itte ita in Japanese}

The Japanese verb $i u$ is typically translated as 'to say' in English, and itta, which is the past-tense form of the verb, is commonly used when the speaker quotes another utterance in his/her own speech. Example (1) demonstrates a typical usage of itta in a quotative utterance.

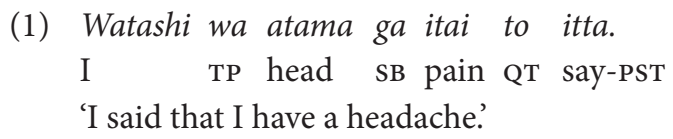

It is also commonly known that itte ita is more likely to be used instead of itta, when the speaker quotes an utterance made by a third-person for the speaker. The frequent usage of itte ita for third-person quotative utterances is also recognized in the field of teaching Japanese as a second language, and itte ita is typically introduced as the standard form for third-person quotations in Japanese language textbooks (Banno et al. 2011, etc.) Example (2) is from a Japanese language textbook, and it demonstrates a typical usage of itte ita in a third-person quotative utterance.

(2) Suu san wa ashita shiken ga aru to itte imashita. Sue Ms. TP tomorrow exam sB exist QT say-te iru-PST

'Sue said that there would be an exam tomorrow'. (Banno et al. 2011, 193)

Itte ita is the past form of the combination of $i u$ and the -te iru construction. The -te iru construction in Japanese is typically labeled as an aspectual marker that marks repetition, continuation, or resultative state (Kindaichi 1950; Soga 1983; Jacobsen 1992; Harasawa 1993, 1994; Kudo 1995; Tsujimura 2007; Iwasaki 2013; McGloin et al. 2013; etc.). However, the usage of the -te iru construction in (2) can be argued to be resulting from -te iru's non-aspectual function, which is the construction's function as an evidential marker of speaker observation (Iwasaki 1993; Yanagisawa 1994, 1995; Fujishiro 1996; Shinzato 2003; Sadanobu and Malchukov 2006, 2011; etc.). The following section briefly summarizes the observation marking function of the -te iru construction in Japanese.

\section{$\mathbf{1 . 2}$-te iru as a marker of speaker observation}

In addition to its well-recognized property as an aspectual marker, the -te iru construction in Japanese possesses a function that specifies the source of the stated proposition to be the speaker's first-hand observation through his/her five senses such as seeing and hearing. In regards to the evidential marking function of the -te iru construction in interactive situations, the following comparison between 
(3) and (4) by Fujishiro (1996) demonstrates how the speaker utilizes its evidential marking function. Assume that the following conversational utterances are made at a hospital.

(3) Nurse 1:

Tanaka-san (patient), kyoo wa chanto gohan tabeta?

Tanaka Mr./Ms. today TP surely meal eat-PST

'Did Mr./Ms. Tanaka (patient) surely eat the meal today?'

Nurse 2:

Ee, kiree ni tabemashita yo./ tabete imashita yo.

yes, completely eat-PST FP eat-te iru-PST FP

'Yes, he/she completely ate it.'

(4) Nurse 1:

Tanaka-san (patient), kyoo wa chan to gohan tabeta?

Tanaka Mr./Ms. today TP surely meal eat-PST

'Mr./Ms. Tanaka, did you surely eat the meal today?'

Tanaka (patient):

Ee, kiree ni tabemashita yo. ${ }^{*}$ tabete imashita yo.

yes, completely eat-PST FP eat-te iru-PST FP

'Yes, I completely ate it.'

(Fujishiro 1996, 5)

In each example, the conversational exchange is assumed to be made after the patient finished eating the meal, in reference to the patient's act of eating. In (3), Nurse 1 asks Nurse 2 whether Tanaka (patient) ate the meal or not, and Nurse 2 can answer the question using either the simple past tense tabemashita 'ate' or tabete imashita, ${ }^{1}$ which includes the past-tense form of the verb taberu 'to eat' and the -te iru construction. In contrast, when Nurse 1 asks the same question directly to the patient as in (4), the patient cannot answer the question with the -te iru construction. The difference between (3) and (4) cannot be explained solely by the aspectual differences between the two sentences, since there is no difference in the temporal properties in the two examples. Fujishiro (1996) argues that this phenomenon is caused by the observation marking function of the -te iru construction, because an individual usually cannot be an observer of his or her own action. If we follow Fujishoro's argument, the -te iru construction in itte ita used in third-person quotative utterances can be interpreted as an evidential marker of observation, since hearing another person's utterance is considered to be a type of observation through one's five senses.

1. Tabemashita and tabete imashita are polite-form variations of tabeta and tabete ita, respectively. 
It must be noted that the notion of "evidentiality" closely relates to the nonaspectual usage of the -te iru construction in Japanese. According to Dendale and Tasmowski (2001), a study conducted by Jakobson (1957) was the first study that brought the term "evidential" into common usage in the field of linguistics. Jakobson claims that an evidential is a label for a verbal category, which indicates the source of information on which the speaker's statement is based. Similarly, Cornille (2009) provides the following definition of evidentials, which is "the functional category that refers to the perceptual and/or epistemological basis for making a speech act" (p. 45). Cornille continues that "[i]n traditional classifications, evidentiality is divided into direct and indirect evidentiality. Direct evidentials are used when the speaker has witnessed the action while indirect evidentials are used when the speaker has not witnessed the action personally but has either deduced the action or has heard about it from others" (p. 45). Thus, it can be said that past studies on the evidential function of the -te iru construction such as Fujishiro (1996) examine the -te iru construction as a type of direct evidential marker that indicates that the source of the uttered proposition is the speaker's first-hand observation.

\section{Remaining issues}

As previously mentioned, it is generally believed that the distinction between itta and itte ita is made based upon who produced the quoted utterance. However, even though some studies have been conducted on the difference between itta and itte ita in the written form of Japanese (Nishi 2015, 2016), the distributional frequency of itta and itte ita in naturally occurring conversations has not been examined in previous studies and remains unexplored. One issue arising from this lack of studies based on the analysis of actual language is the difference between linguists' intuition and the actual forms used by speakers in interactive situations. For example, by analyzing audiotaped natural conversations in Japanese, Ono et al. (2000) demonstrate that the Japanese case particle $g a$ is used to mark "situations where there is something unpredictable about the relationship between the ga-marked NP and the predicate" (p. 65), contrary to the idea that $g a$ is a subject marker of the sentence as argued by grammarians such as Kuroda (1965) and Kuno (1972). Also, the difference between the spoken and written forms of the Japanese language has been a long discussed topic in the field of Japanese linguistics. Shibatani (1990) states that "the colloquial language and the written language show different characteristics, and perhaps even more so in Japanese than in English and other European languages" (p. 359). If Shibatani's statement truly reflects the systematic separation between the spoken and written forms of Japanese, the usage of itta and itte ita could be one of the items that is differentiated between the two forms of the language. 
In regards to the interchangeability of itta and itte ita, it is not completely unacceptable to use itte ita for quoting one's own utterance, and using itta for quoting a third-person's utterance is not necessarily unacceptable either. Examples (5) and (6) demonstrate the use of itte ita and itta for first- and third-person quotations, respectively.

(5) Watashi wa atama ga itai to itte ita. I TP head sв pain QT itte ita 'I said that I have a headache.'

(6) Takashi wa atamaga itai to itta. Takashi TP head pain QT itta 'Takashi said that he has a headache.'

In (5), the -te iru construction is used with $i u$ in a first-person quotative utterance, and this sentence is not necessarily syntactically ill-formed even though the speaker is less likely to utter sentences such as (5). In addition, itta, which is the form without the -te iru construction, is used in (6). Using itta for a third-person utterance as in (6) also does not exhibit a problem at the sentential level, but it deviates from the generally believed usage of itte ita in third-person quotative utterances. Furthermore, speakers may actively choose to use itte ita for quoting his or her own utterance, as well as itta for a quoting a third-person utterance. If using itte ita is truly the default choice for quoting a third-person utterance, the speaker may be able to create some kind of interactional effects by intentionally choosing to use itta to deviate from the default pattern. Similarly, if the speaker uses itte ita to quote his or her own utterance, it might be an active choice that is purposefully intended to create certain interactional effects by deviating from the standard pattern.

\section{Present study}

In order to explore the actual usages of itta and itte ita and how they are differentiated from one another in naturally occurring conversations, the present study examined audio recordings of naturally occurring conversations between L1 speakers of Japanese, and provide an overview of the usages of itta and itte ita in quotative utterances in Japanese.

The present study examined the audio recordings of naturally occurring conversations in Japanese from the CallFriend corpus on Talkbank (MacWhinney 2007), which is a public online database for linguistic research. The CallFriend corpus includes 32 separate audio recordings of telephone conversations between L1 speakers of Japanese. The total length of recorded conversations in the corpus is approximately 13 hours and 11 minutes. Since most of the recordings were 
conversations between close friends, the speech style adopted by the speakers was mostly the so-called casual style (non-polite style). Some geographical variations were found in the data, but the effect of the variations on the present study is considered to be minimal. In the transcriptions of the data used in the present study, pseudonyms are used for proper nouns such as names of people and places.

\section{Results and analysis}

In the CallFriend corpus, 215 cases of quotative utterances made with itta or itte it $a$ were found. The author of the present study categorized those cases into three categories based on who produced the quoted utterance. There were 6 cases of itta and itte ita in which the producer of the quoted utterance was not identifiable from the contextual information of the conversation, therefore those cases were excluded from analysis. Some morphological variants of itta and itte ita, such as iimashita and itteta, were found in the data. Those variants are included in the counts of itta and itte it $a$ in order to minimize unrelated complexities for the present study. The following table is a summary of the distribution of itta and itte ita in the examined corpus.

Table 1. Summary of itta and itte ita in the CallFriend Corpus

\begin{tabular}{lccc}
\hline & First-person 'I said' & Second-person 'you said' & Third-person 'he/she said' \\
\hline itta & $41(91.1 \%)$ & $1(10.0 \%)$ & $35(22.7 \%)$ \\
itte ita & $4(8.9 \%)$ & $9(90.0 \%)$ & $119(77.3 \%)$ \\
Total & 45 & 10 & 154 \\
\hline
\end{tabular}

\subsection{Dominant patterns for itta and itte ita}

As shown in Table 1, when the producer of the quoted utterance is the speaker himself/herself, itta was used in $91.1 \%$ of the cases. This finding supports the generally held idea on the usages of $i t t a$, which is first-person quotations are mostly made with itta, not itte ita.

The following excerpt is from the examined corpus, which includes a case of itta that is being used in a first-person quotative utterance. In (7), two male conversationalists are talking about sending and receiving documents via mail.

(7) [CallFriend: japn6164]

1 Taka: Un.

$$
\begin{aligned}
& \text { mhm } \\
& \text { 'Mhm.' }
\end{aligned}
$$




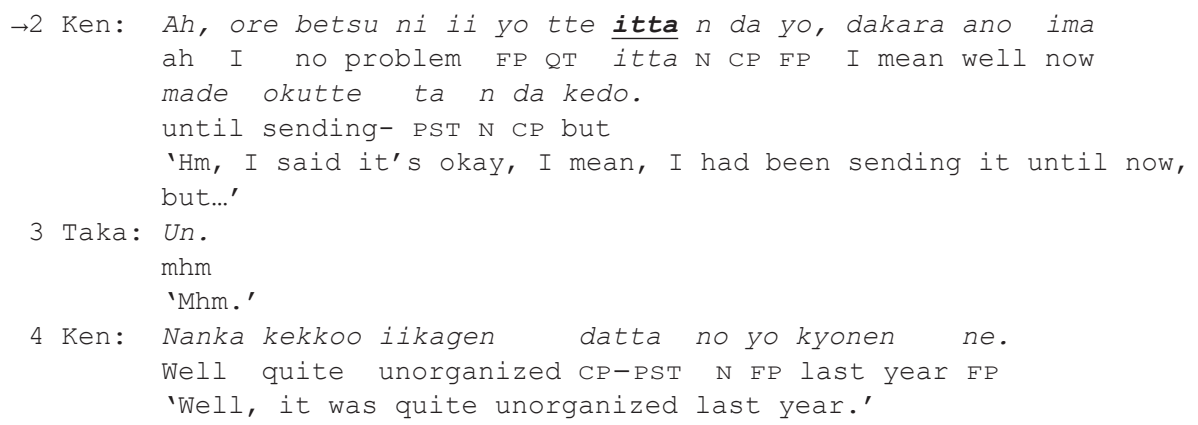

In line 2 in (7), Ken utters itta in a quotative utterance, and the producer of the quoted utterance is Ken himself as indicated by the use of the first-person pronoun ore 'I.' The majority of first-person quotative utterances in the examined corpus were made with itta as we saw in Table 1, and this indicates that the simple-past itta is the dominant form for first-person quotations in naturally occurring conversations in Japanese.

For third-person quotative utterances, itte ita seems to be the default form due to the high percentage in the examined corpus. As shown in Table 1, 77.3\% of the third-person utterances in the corpus were made with itte ita. This confirms the generally recognized high frequency of itte ita in third-person quotative utterances, and it is also compatible with the instruction to use itte ita for third-person quotations in textbooks for learners of Japanese (i.e. Banno et al. 2011). The following excerpt includes a case of itte ita used for a third-person quotative utterance. In (8), Masa and Yumi are talking about a mutual acquaintance with whom they find it difficult to carry on a conversation.

(8) [CallFriend: japn1841]

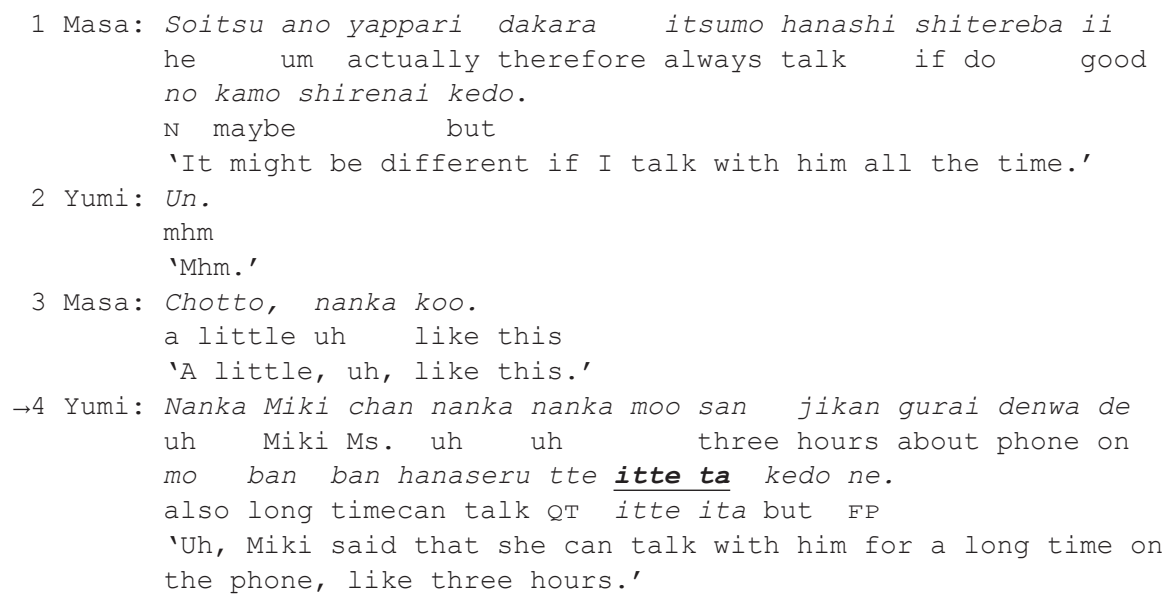




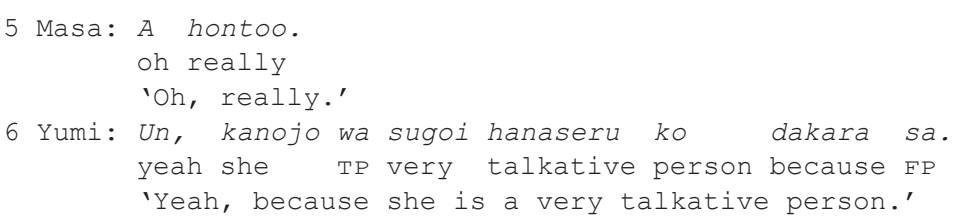

In line 4 of the above excerpt, Yumi quotes what Miki said by using itte ta, which is one of the colloquial variations of itte ita. As we can infer from the contextual information in the excerpt, Miki is a third-person for Yumi, and Yumi was an observer of Miki's act of making the quoted utterance. More precisely, when Miki performed the act of making the quoted utterance, Yumi was involved in the event as an observer, not as the performer. Considering how Yumi and Miki were involved in the event of the production of the quoted utterance, the usage of the -te iru construction in itte ta in line 4 appears to be resulting from its evidential marking function of speaker observation from Yumi's perspective, since Miki is a third-person for Yumi.

Examples (7) and (8) demonstrated the typical usages of the itta and itte ita for first-person and third-person quotative utterances, respectively. The majority of cases of itta and itte ita follow the same pattern, but the quantitative overview of the corpus also shows that there are several cases of itta and itte ita that deviate from the dominant pattern. In the following section, some of the deviant cases will be qualitatively analyzed in order to explore the factors that contribute to the occurrence of deviant cases.

\subsection{Deviant cases}

\subsection{1 itte ita used for first-person utterances}

The majority of first-person quotations are made with itta in the examined corpus, but several cases of first-person quotations made with itte ita were also found. Out of the four cases of itte ita used for first-person utterances in the corpus, two of them exhibited the aspectual properties of repetition or resultative state, which can be explained by the -te iru construction's aspectual marking function. However, there were cases of itte ita that did not necessarily exhibit the aspectual properties that are typically marked with the -te iru construction. The following excerpt demonstrates such usages of itte ita.

Excerpt (9) is a conversation between a mother (Aki) and her son (Yoshi), which includes two cases of itte ita used for first-person utterances. Shortly before the beginning of (9), the two conversationalists started talking about the idea of purchasing a new car for Yoshi, and giving Yoshi's current car to his younger sister, Misako. While talking about the idea, Yoshi has expressed his reluctance to the idea of purchasing a new car due to financial reasons. 
(9) [CallFriend: japn1612]

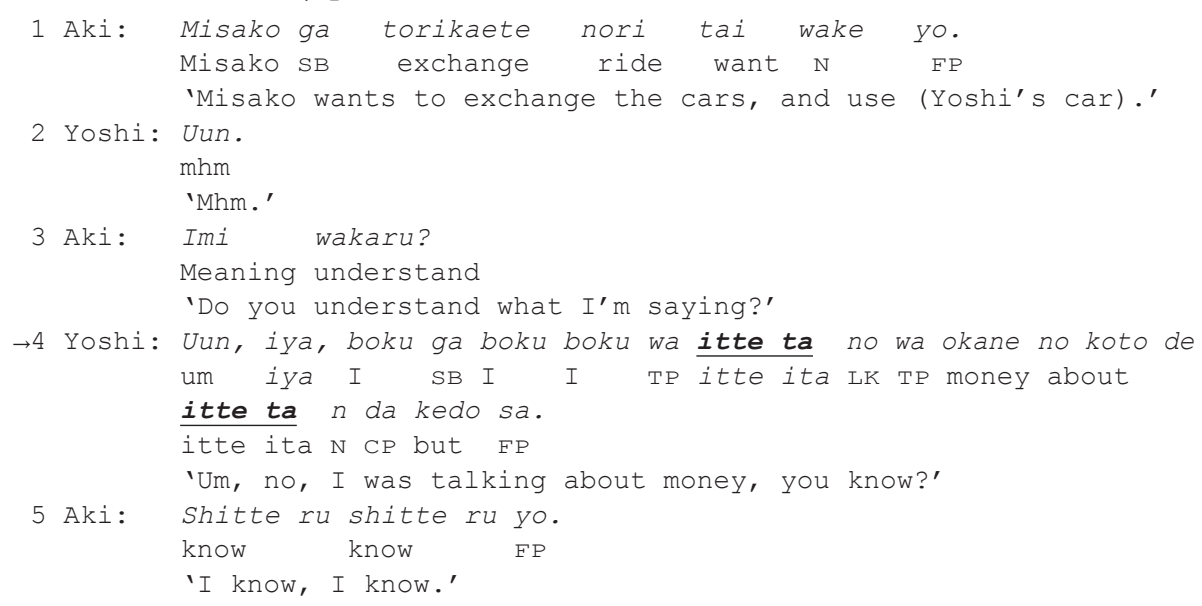

In line 4, Yoshi uses itte ta when he quotes what he said as indicated by the first-person pronoun boku 'I.' This usage of itte ta for a first-person quotative utterance deviates from the dominant distributional pattern found in the corpus. However, if we pay close attention to the evidential marking function of the -te iru construction and the perspective from which the quoted utterance is expected to be recognized, the occurrence of itte ita in line 4 can be explained.

Iwasaki (1993) demonstrates how using the -te iru construction for a first-person action influences the pragmatic interpretation of the utterance.

(10) Boku wa biru o nagutta.

I TP Bill o hit-PST

'I hit Bill.'

(11) Boku wa biru o nagutte ita.

I TP Bill o hit-te iru-PST

'(I realized then that) I had hit bill.'

(Iwasaki 1993, 28)

According to Iwasaki, (10) is uttered when the action of hitting Bill was the speaker's conscious act. On the other hand, when the -te iru construction is used for a first-person action as in (11), it indicates that the speaker was not aware of what he was doing when he hit Bill, and then realized what he had done after the completion of the action. Iwasaki argues that this can be confirmed by the fact that kiga tsuitara 'when I realized' can appear with (11) but not with (11). In addition, according to Iwasaki, the speaker employs the S-perspective (S stands for SELF) in (10), with which the speaker presents the information as a subjective experience. In contrast, in (11), the information is presented from the O-perspective (O stands for OTHER), from which the speaker indicates his/her observer role towards the 
stated information. Iwasaki's comparison between (10) and (11) demonstrates that the speaker's unconscious act can be marked with the -te iru construction, since when a speaker recognizes his or her unconscious action after its completion, the speaker is more like an objective observer even though the action was technically performed by the speaker.

However, as for the usage of the -te iru construction in line 4 in excerpt (9), it is difficult to interpret that Yoshi was in an unconscious state when he previously expressed his reluctance to purchase a new car, even though the -te iru construction is used to refer to his own action. In regards to the usage of the -te iru construction in itte ta in line 4 in (9), what is similar to Iwasaki's demonstration is the perspective from which the stated action is seen. That is, in Iwasaki's demonstration of the speaker hitting Bill, the speaker was in an unconscious state when he hit Bill, and as a result, the speaker's own action is presented as if he or she recognized the action as an observer. In line 4 in (9), Yoshi presents the action denoted by the verb $i u$ from an observer's perspective with the -te iru construction. However, this does not necessarily indicate that Yoshi did not realize what he did until the action was completed. In line 4, the person who is marked as an observer is Aki, not Yoshi. The following is the detailed explanation for the occurrences of itte ta in line 4.

In line 4 in (9), after the initial filler uun 'um,' Yoshi utters iya, which can be interpreted as an expression of contradiction (Saft 1998), and/or what Hayashi and Kushida (2013) call resistance to a question. That is, by uttering iya, Yoshi appears to be challenging the presupposition held in Aki's question in line 3, which is that Yoshi's concern is about the logistics of managing the two cars owned by the family. With regards to the usage of itte ta for quoting Yoshi's own utterance, the usage of itte $t a$, which includes the -te iru construction, seems to have the effect of delivering his own utterance from Aki's perspective. More precisely, by making use of the observation marking function of the -te iru construction in itte ta, Yoshi frames his own action of making an utterance as something that was observed by Aki, rather than an action that Yoshi subjectively experienced. In other words, using itte ta instead of itta in line 4 creates the effect of describing what Yoshi did from Aki's perspective, meaning what you heard was that... instead of $I$ said that....

The reason for choosing itte ta over itta in line 4 appears to be highly relevant to the fact that line 4 is uttered as an explanation for what Yoshi previously said to Aki. Based on the contextual information for Excerpt (9), we can infer that Aki has heard what Yoshi previously said, but Yoshi is questioning Aki's understanding of Yoshi's statement. Yoshi made the utterance in line 4 in order to provide more 
information to assist Aki in understanding what she heard from Yoshi, which is about how Yoshi's utterance should be understood from Aki's perspective. The usage of the -te iru construction for Yoshi's own action in line 4 aligns with the -te iru construction's function to mark an objective observation, since Yoshi's utterance in line 4 was made as an explanation that focuses on understanding his previous statement from Aki's perspective. As demonstrated by the cases of itte ita in Excerpt (9), it is possible for a speaker to choose to use itte ita for his/her own utterances when it is intentionally delivered as something the addressee heard from his/her perspective, and this can be seen as a way to manipulatively make use of the -te iru construction's evidential marking function.

As a final note, it must be noted that Yoshi's recollection of his previous statement might have been another factor that has contributed to the occurrence of itte ita in (9). In general, when a speaker recalls what he/she did in the past, it is somewhat similar to recognizing what he/she did unconsciously after the completion of the action. That is, when the speaker is not sure about or has forgotten what he/she did in the past, and then he/she recalls what he/she did, the recognition process resembles noticing one's unconscious action from an objective perspective afterwards. Therefore, if Yoshi has just recalled what he said in the past along with the conversation in (9), the situation would be similar to the demonstration by Iwasaki (1993) in (11), since both of them involve the recognition of the speaker's own action from an objective perspective.

This section has explored an example that includes itte ita that is used to refer to the speaker's own act of making an utterance. The next section will discuss the factors that are relevant to the usage of itta for quoting third-person utterances.

\subsection{2 itta used for third-person utterances}

In the examined corpus, the majority of third-person quotations were made with itte ita, however there were also cases of third-person utterances quoted with itta. The cases of itta used for third-person quotations were qualitatively examined, and it was found that the psychological impact of the quoted utterance for the speaker seems to be related to the choice between using itta and itte ita for third-person utterances. More precisely, when a quoted third-person utterance has a high psychological impact for the speaker, itta is likely to be used instead of itte ita.

Excerpt (12) includes a case of itta used for a third-person quotation with high psychological impact for the speaker. In (12), the two female conversationalists, Kayo and Mari, talk about Mari's experience of having a crush on a homosexual man, and getting rejected by him later. 


\section{(12) [CallFriend: japn1684]}

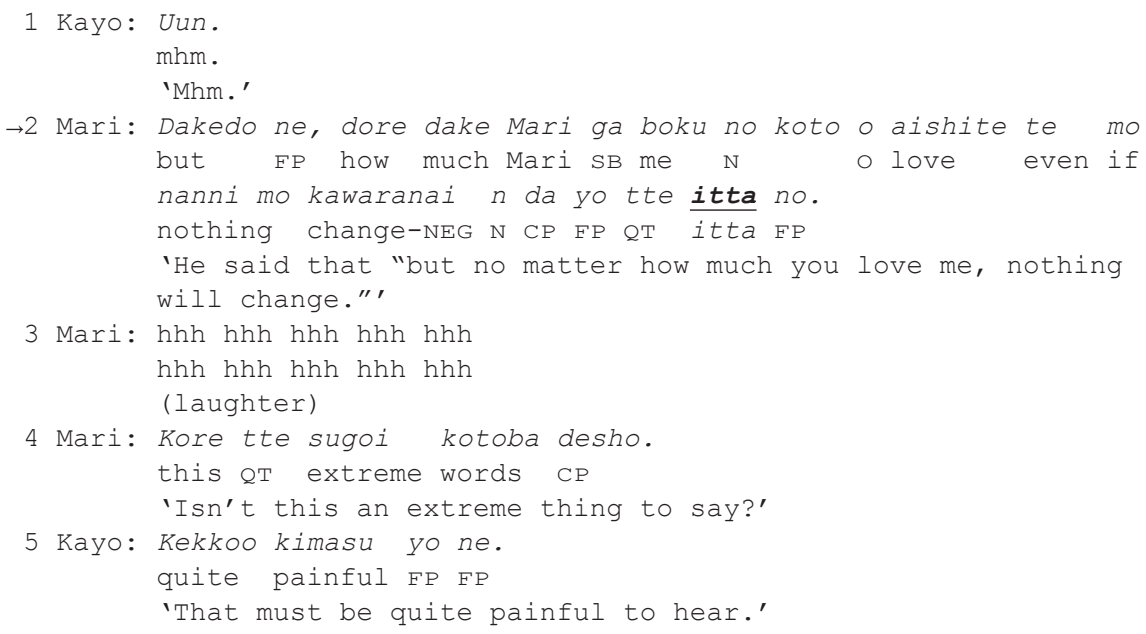

Along with the conversation about the homosexual man who rejected Mari, in line 2, Mari utters itta to quote what he said. Since the man who rejected Mari is a third-person for Mari, the occurrence of $i t t a$ in line 2 deviates from the dominant pattern. In regards to the psychological impact of the quoted utterance, Mari describes what the man said as sugoi kotoba 'an extreme thing to say', and this shows that the man's utterance had a strong psychological impact on her.

The speaker's choice between itta and itte ita in line 2 can be further explored if we intentionally replace itta in line 2 with itte ta. ${ }^{2}$ If itte ta was used in line 2, most readers would feel that Mari is psychologically indifferent to what the man said, and this indifference would be inconsistent with her description of his utterance in line 4. The following section further discusses how the -te iru construction can be effectively used in order to mark the speaker's psychological impact towards the stated information.

\subsection{3 -te iru and psychological impact}

In regards to the effect of the psychological impact on the choice between itta and itte ita, what Yanagisawa (1995) argues seems to be relevant here. Even though the basis for Yanagisawa's argument is solely based on his intuitive judgment and he does not provide further analysis, Yanagisawa's examples demonstrate how the psychological impact of the quoted utterance affects the choice between itta and itte ita. Assume that (13) and (14) are uttered after a phone conversation between the addressee of the utterance and his or her grandmother.

2. The casual variant itte ta is used here because it is more suitable for the level of formality in the ongoing conversation. 
(13) Obaachan nan te itteta no? grandma what QT itte ita FP

'What did grandma say?'

(14) Obaachan nan te itta no?

grandma what QT itta FP

'What did grandma say?

(Yanagisawa 1995, 210)

(13) includes the -te iru construction while (14) does not. According to Yanagisawa, (13) would be selected in most situations, but (14) is likely to be selected when the exact phrase uttered by the grandmother is crucial for determining the amount of monetary inheritance from her. Needless to say, the amount of monetary inheritance is normally considered to be psychologically significant for the speaker. What this comparison indicates is that when the content of the quoted third-person utterance is highly significant for the speaker, itta may be selected over itte ita even when the quoted utterance was produced by a third-person for the speaker.

With regards to case of itta in line 2 in Excerpt (12), the occurrence of itta seems to be similar to Yanagisawa's demonstration regarding the effect from the psychological impact of the quoted utterance. In (12), a third-person utterance that had a strong psychological impact on the speaker is quoted by the speaker, and itta is used instead of the dominantly-occurring itte ita. This usage of itta in (12) highly resembles Yanagisawa's demonstration of the distinction between using itta and itte ita. The cause of the high level of psychological impact may be different between the case of itta between (12) and Yanagisawa's demonstration in (14). However, the importance of the quoted utterances is recognized to be high by the speaker in both examples, and this impact appears to be contributing to the occurrence of itta over itte ita.

Furthermore, if we see the -te iru construction as an evidential marker that shares many properties with other evidential markers in general, what Kamio (1994) argues also becomes relevant to the difference between itta and itte ita. By using his well-known notion of territory of information, Kamio analyzes the pragmatic effects resulting from using evidential markers for sentences pertaining to events with high psychological impact. In order to highlight the pragmatic effects created by using and not using the hearsay evidential markers -tte and -soo, both of which mean 'I heard that,' Kamio conducts a comparison between the following three sentences. Assume that the speaker is Taro's father in each of (15), (16), and (17).

$$
\begin{aligned}
& \text { Taroo wa byooki desu. } \\
& \text { Taro TP sick CP } \\
& \text { 'Taro is sick.' }
\end{aligned}
$$


??Taroo wa byooki desu tte.

Taro TP sick CP heard

'I heard that Taro is sick.'

?? Taroo wa byooki da soo desu.

Taro TP sick CP heard CP

'I heard that Taro is sick.'

(Kamio 1994, 72-73)

According to Kamio, (15) does not sound strange as an utterance uttered by a father whose son is sick, but (16) and (17) sound somewhat strange, since these sentences give an impression that the father is indifferent to his own son's illness. Kamio argues that highly personal information is typically expressed without evidential markers regardless of how the information was accessed. What Kamio argues also indicates that when a piece of information is stated with an evidential marker, the information is usually not highly personal for the speaker.

Generally speaking, when a father is expected to be concerned about his son's illness, and the fact that his son is sick is a highly personal and psychologically significant for the father. However, since using evidential markers also marks psychological distance towards the stated propositional information in addition to how the information was accessed, using evidential markers such as -tte and -soo as in (16) and (17) indicates that the speaker is psychologically distant from the propositional information. As a result, sentences such as (16) and (17) sound strange as an utterance by a father whose son is sick.

As for the case of itta in excerpt (12), using itta instead of itte ita is compatible with what Kamio argues, since the -te iru construction's evidential nature contributes to expressing psychological distance between the speaker and the stated propositional information. As mentioned earlier, a third-person quotation is typically made with itte ita, but in (12), a third-person utterance is quoted with itta. If we follow Kamio's analysis of the effects resulting from using or not using evidential markers, the non-usage of the -te iru construction in (12) exhibits that the psychological distance between the speaker and what the homosexual man said was close, and the quoted utterance had a strong psychological impact on the speaker, which is also compatible with the description by the speaker, sugoi kotoba 'an extreme thing to say.'

In regards to the notion of psychosocial impact, it should be noted that the factors that determine the level of psychological impact are unique to each conversational situation, such as the emotional reaction to the quoted utterance, the possible future outcome that could be brought from stating the quoted utterance, and the way the quoted utterance was phrased, etc. However, whenever a quoted third-person utterance is highly important for the speaker, the psychological impact that comes from that importance contributes to the usage of $i t t a$, which is a form without an evidential marker. 


\subsection{4 itta for second-person utterances}

The examined corpus included 10 cases of second-person quotations ('you said that...'). Itte ita was used in 9 out of the 10 cases of second-person quotations in total. This high frequency of itte ita (90\%) can be explained by the -te iru construction's evidential marking function as was the case for third-person quotative utterances, since the speaker was an observer of another person's act of making the quoted utterance in second-person quotations.

There was one deviant case of second-person quotative utterance made with itta in the corpus. The following excerpt includes the case of $i t t a$. (18) is from a conversation between two female native speakers of Japanese.

(18) [CallFriend: japn6698]

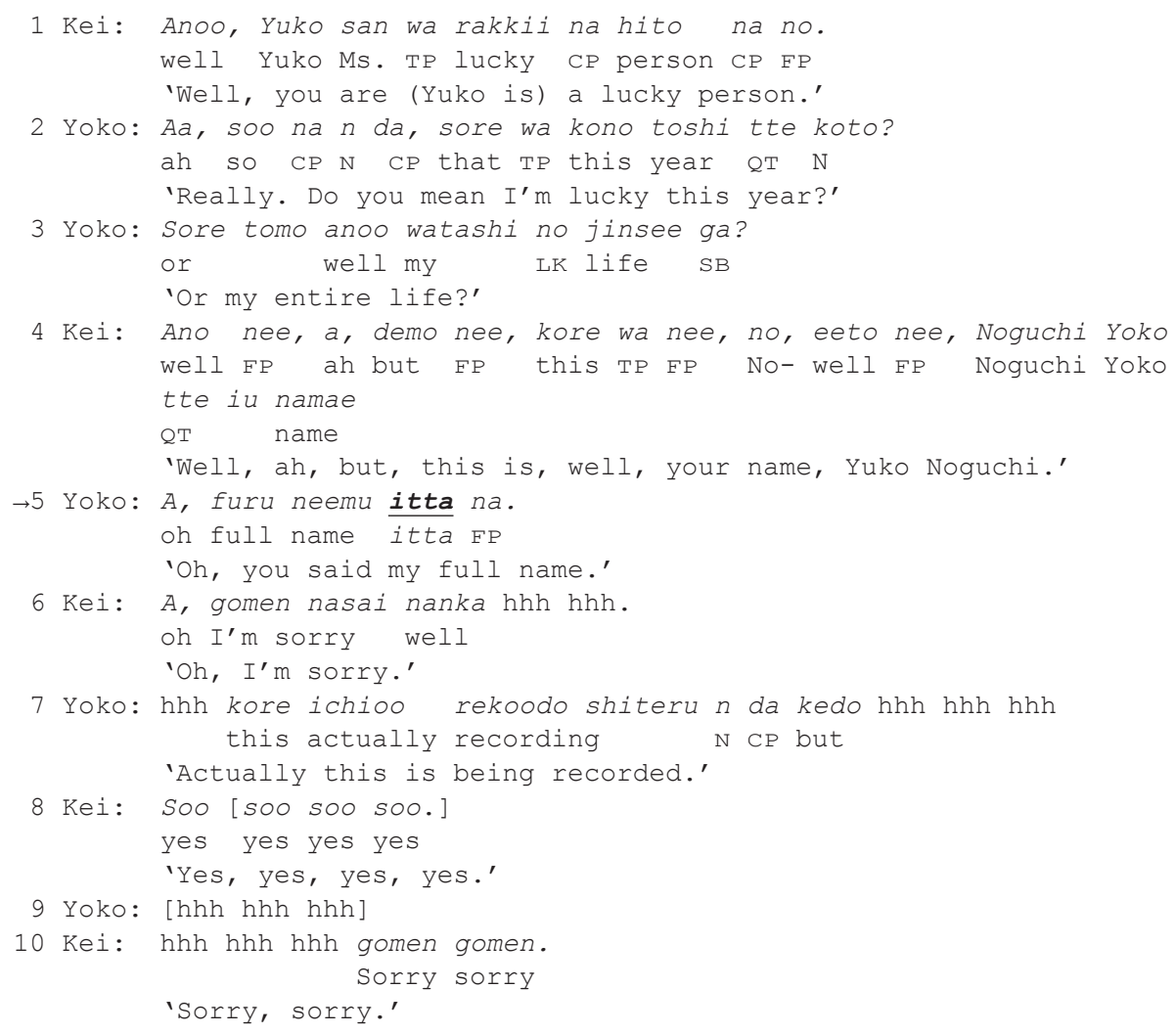

In line 5 in (18), Yoko uses itta to refer to what Kei said, who is a second-person for Yoko. Unlike the other 9 cases of second-person quotations in the examined corpus, itta is used for a second-person utterance in line 5. Similar to the cases of itta in third-person quotative utterances, the usage of $i t t a$ for a second-person utterance in line 5 can be explained by the notion of psychological impact. In the utterance in line 5, Yoko utters a, furu neemu itta na 'oh, you said my full name' in reference to 
what Kei said in line 4 . The two conversationalists, Yoko and Kei, were aware of the fact that their conversation was being recorded for research purposes at the time of the conversation, and they were also aware that their personal information would be disclosed if it was included in the recording. Considering the numerous laughter tokens by the two conversationalists in lines 6 through 10, and the three cases of gomen 'sorry' in lines 6 through 10, it is clear that stating Yoko's full name was recognized as a psychologically impactful utterance by both of the conversationalists. In addition, Yoko's utterance in line 5 and Kei's utterance in line 6 both start with $a$ 'oh, which can be interpreted as a marker of an "exclamatory sentence" (Iwasaki, 2013, 287), and this also shows that uttering Yoko's full name was recognized as an act that was psychologically impactful. Considering the various indicators that show the high level of psychological impact, the usage of itta instead of itte ita for a second-person in (18) seems to be triggered by the high level of psychological impact, and this is analogues to the case of a third-person quotation made with itta in (12).

\section{Conclusion}

This paper has provided an overview of quotative utterances made with iu 'to say' in naturally occurring conversations in Japanese. The results of the present study demonstrated that the simple-past itta is mostly used in first-person quotative utterances. For second- and third-person quotative utterances, itte ita, which includes the -te iru construction, is used in the majority of cases. The usage of itte ita in second- and third-person quotative utterances appears to be resulting from the -te iru construction's non-aspectual function, which marks that the speaker observed the action performed by a second- or third-person. The paper also examined several deviant cases found in the data, in which itte ita is used for first-person utterances, and itta is used for second- and third-person utterances. Based on the qualitative analysis of each case, it was concluded that when the quoted utterance has a high level of psychological impact for the speaker, itta is more suitable than itte ita since using the -te iru construction as an evidential marker intrinsically marks that the speaker is psychologically distant from the stated propositional content.

Finally, it must be noted that psychological impact is not the only variable that affects the choice between itta and itte ita in second- and third-person quotative utterances. One other variable that can affect the choice between the two forms is what Smith $(2003,2005)$ calls the mode of discourse. According to Smith, narrative is a mode of discourse in which multiple events are listed in the temporal order, and "narrative time advances with perfective event sentences, and with explicit temporal adverbials, and fails to advance otherwise" (Smith 2005, 11). What Smith 
argues is also applicable to Japanese, and in order for the narrative time to advance, the perfective (simple past-tense) endings must be used to indicate the endpoint of each listed event. For this reason, when the verb $i u$ is used in a segment where the discourse is structured as narrative, itte ita, which includes the -te iru construction, cannot indicate the progression of narrative time due to the atemporal nature of the -te iru construction. The examined data for the present study did not include a clear segment of oral narrative, and iu's usage in oral narrative discourse remained unexplored. Examining oral discourse that includes clear segments of narrative, such as story telling in front of a large audience, may contribute to further analysis of itta and itte ita in the spoken version of Japanese.

\section{References}

Banno, Eri, Yoko Ikeda, Yutaka Ohno, Chikako Shinagawa, and Kyoko Tokashiki. 2011. Genki I: An Integrated Course in Elementary Japanese. Tokyo: The Japan Times.

Cornillie, Bert. 2009. "Evidentiality and Epistemic Modality: On the Close Relationship between Two Different Categories." Functions of Language 16 (1): 44-62. doi:10.1075/fol.16.1.04cor

Dendale, Patrick, and Liliane Tasmowski. 2001. "Introduction: Evidentiality and Related Notions." Journal of Pragmatics 33 (3): 339-348. doi:10.1016/S0378-2166(oo)0ooo5-9

Fujishiro, Hiroko. 1996. "Shiteita no moohitotsu no kinoo: Kanchi no shiten o arawasu shiteita [Another function of shiteita: Viewpoint of perception exhibited by shiteita]." Nihongo Kyooiku 88: 1-12.

Harasawa, Isao. 1993. "Teiru no kinoo [Functions of teiru]." Nihongogaku Ronsetsu Shiryoo 30 (3): 87-99.

Harasawa, Isao. 1994. "A Pragmatic View of V-te-i-ru and V-te-ar-u." Journal of Pragmatics 22: 169-197. doi:10.1016/0378-2166(94)90066-3

Hayashi, Makoto, and Shuya Kushida. 2013. "Responding with Resistance to Wh-questions in Japanese Talk-In-Interaction.” Research on Language \& Social Interaction 46 (3): 231-255. doi: 10.1080/08351813.2013.810407

Iwasaki, Shoichi. 1993. Subjectivity in Grammar and Discourse. Amsterdam/Philadelphia: John Benjamins.

Iwasaki, Shoichi. 2013. Japanese: Revised Edition (Vol. 17). Amsterdam/Philadelphia: John Benjamins. doi:10.1075/loall.17

Jacobsen, Wesley. M. 1992. The Transitive Structure of Events in Japanese. Tokyo: Kuroshio.

Jakobson, Roman. 1957. "Shifters, Verbal Categories and the Russian Verb." Harvard University, Dept. of Slavic Languages and Literatures, Russian Language Project.

Kamio, Akio. 1994. “The Theory of Territory of Information: The Case of Japanese." Journal of Pragmatics 21 (1): 67-100. doi:10.1016/0378-2166(94)90047-7

Kindaichi, H. 1950, in 1976. Nihongo Dooshi no Asupekuto [Aspect and Japanese Verbs]. Tokyo: Mugi Shoboo.

Kudo, Mayumi. 1995. Asukekuto, Tensu Taikee to Tekusuto [Aspect, Tense, and Text]. Tokyo: Hitsuji Shoboo. 
Kuno, Susumu. 1972 "Functional Sentence Perspective: A Case Study from Japanese and English." Linguistic Inquiry 3: 269-320.

Kuroda, S. Y. 1965. “Generative Grammatical Studies in the Japanese Language.” Doctoral Dissertation, Massachusetts Institute of Technology.

McGloin, Naomi. H., M. Endo Hudson, Fumiko Nazikian, and Tomomi Kakegawa. 2013. Modern Japanese Grammar: A Practical Guide. London and New York: Routledge.

MacWhinney, Brian. 2007. “The TalkBank Project.” In Creating and Digitizing Language Corpora: Synchronic Databases, 1: 163-180. Houndmills: Palgrave-Macmillan.

Nishi, Hironori. 2015. "The Difference Between iimashita and itte imashita in Quotative Utterances: Mode of Discourse and Pedagogical Implications." 2015 CAJLE Conference Proceedings 222-231.

Nishi, Hironori. 2016. "Non-Aspectual Functions of the Japanese Aspectual Marker -te iru." Doctoral Dissertation, University of Wisconsin-Madison.

Ono, Tsuyoshi., Sandra A. Thompson, and Ryoko Suzuki. 2000. "The pragmatic Nature of the so-called Subject Marker $g a$ in Japanese: Evidence from Conversation.” Discourse studies 2 (1): 55-84. doi: 10.1177/1461445600002001003

Sadanobu, Toshiyuki, and Andrej Malchukov. 2006. "Ebidensharitii to gendai nihongo no 'te iru' koobun [Evidentiality and the teiru Structure in Modern Japanese]." In Gengo ni arawareru 'seken' to 'sekai' ed. by Masayuki Nakagawa, and Toshiyuki Sadanobu, 153-166. Tokyo: Kuroshio Shuppan.

Sadanobu, Toshiyuki, and Andrej Malchukov. 2011. "Evidential Extension of Aspectotemporal Forms in Japanese from a Typological Perspective." In the Mood for Mood (Cahier Chronos 23), 141-158.

Saft, Scott. 1998. "Some Uses and Meanings of Utterance Initial iya in Japanese Discourse." Japanese/Korean Linguistics 7: 121-37.

Shibatani, Masayoshi. 1990. The Languages of Japan. New York: Cambridge University Press.

Shinzato, Rumiko. 2003. "Experiencing Self Versus Observing Self: The Semantics of Stative Extensions in Japanese." Language Sciences 25 (2):211-238. doi:10.1016/So388-0001(01)00025-0

Soga, Matsuo. 1983. Tense and Aspect in Modern Colloquial Japanese. Vancouver: University of British Columbia Press.

Smith, Carlota. S. 2003. Modes of Discourse: The Local Structure of Texts. Cambridge: Cambridge University Press. doi:10.1017/CBO9780511615108

Smith, Carlota. S. 2005. "Aspectual Entities and Tense in Discourse." Studies in Natural Language and Linguistic Theory 62 (2): 223-237. doi:10.1007/1-4020-3033-9_10

Tsujimura, Natsuko. 2007. An Introduction to Japanese Linguistics (2nd edition). Oxford: Blackwell. Yanagisawa, Hiroya. 1994. “Teiru kei no hi asupekuto imi: Teiru kee no hookokusee [Non-aspectual meanings of the teiru form: Teiru's reporting function]." In Gengo Bungaku Kokugo Kyooiku, ed. by Muneaki Morino, 165-178. Tokyo: Sanshoodoo.

Yanagisawa, Hiroya. 1995. "Teiru kee no hi asupekuto imi 2: Hookokusee no shatee [The teiru form's non-aspectual meanings: Range of report].” Jinbunka Kyooiku Kenkyuu 22: 207-214. 
Appendix. Transcription conventions and abbreviations

$\begin{array}{ll}\text { CP } & \text { various forms of copula verb be } \\ \text { FP } & \text { final particle } \\ \text { LK } & \text { nominal linking particle } \\ \text { NOM } & \text { nominalizer } \\ \text { NEG } & \text { negative morpheme } \\ \text { O } & \text { object marker } \\ \text { PST } & \text { past tense } \\ \text { Q } & \text { question marker } \\ \text { QT } & \text { quotative marker } \\ \text { SB } & \text { subject marker } \\ \text { TP } & \text { topic marker } \\ \text { ( ) } & \text { unintelligible segment } \\ \text { hhh } & \text { laughter } \\ \text { [ } & \text { the point where overlapping talk begins } \\ \text { ] } & \text { the point where overlapping talk ends }\end{array}$

\section{Author's address}

Hironori Nishi

University of Memphis

Memphis, Tennessee 38152

United States

hnishi1@memphis.edu 
